\section{Gategory}

Metal-Mediated

Synthesis

\section{Key words}

amination

silyl ketene acetals

$\alpha$-amino esters

copper

T. MIURA, M. MORIMOTO, M. MURAKAMI* (KYOTO UNIVERSITY, JAPAN)

Copper-Catalyzed Amination of Silyl Ketene Acetals with $\mathrm{N}$-Chloroamines

Org. Lett. 2012, 14, 5214-5217.

\title{
Copper-Catalyzed Amination of Silyl Ketene Acetals with $\mathbf{N}$-Chloroamines
}

Significance: A copper-catalyzed amination reaction of silyl ketene acetals with $N$-chloroamines under mild reaction conditions has been developed. The formation of the corresponding $\alpha$-amino esters is catalyzed by a copper(l)-2,2'-bipyridyl complex which furnishes them in high yield.
Comment: According to the authors, the bulky silyl group disfavors the formation of unwanted byproducts and improves the yield of the desired $\alpha$ amino ester. Furthermore, the facile availability of $\mathrm{N}$-chloroamines from secondary amines with NCS permits a one-pot, two-step synthesis, especially if the $\mathrm{N}$-chloroamine is too unstable for isolation. 